\title{
LA NATURALEZA JURÍDICA DE LA POSIBILIDAD DE PRESCRIPCIÓN DE LOS DELITOS
}

\author{
THE LEGAL NATURE OF THE STATUTE OF LIMITATIONS \\ FOR CRIMINAL OFFENSES
}

MANUEL CERRADA MORENO

Doctor en Derecho. Juez sustituto

Recibido: 04/09/2017

Aceptado: 05/10/2017

\begin{abstract}
Resumen: Tradicionalmente, la prescripción de los delitos ha sido estudiada como una institución a la que se ha asignado una naturaleza jurídica material o procesal para derivar de ello consecuencias mediante el sistema lógico-deductivo, pero de este modo se llega a resultados que no son válidos, pues contradicen lo dispuesto en normas con rango jerárquico superior en el ordenamiento jurídico. En cambio, la posibilidad de prescripción puede ser vista como una cualidad de los delitos que afecta a su punibilidad. Esta concepción, más acorde con la existencia de delitos imprescriptibles, permitiría la celebración del juicio con independencia del tiempo transcurrido desde la comisión del delito, como medida de dignificación y reparación de las víctimas, aunque después, por razones de falta de la necesidad, la pena no se imponga o no se ejecute.
\end{abstract}

Palabras clave: prescripción del delito, posibilidad de prescripción, extinción de la responsabilidad penal, naturaleza jurídica de la prescripción, metodología jurídica

\begin{abstract}
Traditionally, the statute of limitations of criminal offences has been studied as an institution to which a material or procedural legal nature has been ascribed and by which consequences are derived based on a logical-deductive system. However, this method gives rise to results which are not valid, given that they contradict the provisions found in higher level laws. However, the possibility of applying a statute of limitations to criminal offences may be seen as a quality of the offences that affects whether or not they are punishable. This view, which is more in accordance with the existence of criminal offences in which the statute of limitations can never be applied, would allow a trial to be held irrespective of the time that has elapsed since the criminal offence was committed, as a measure to compensate and uphold the dignity of victims, even if no penalty is subsequently imposed or enforced because this is deemed unnecessary.
\end{abstract}

Keywords: statute of limitations, possibility of applying a statute of limitations, lapse of criminal liability, legal nature of the statute of limitations for criminal offenses, legal methodology.

SUMARIO: 1. PLANTEAMIENTO DEL TEMA 2. LA PRETENDIDA UTILIDAD DEL DEBATE SOBRE LA NATURALEZA JURÍDICA DE LA PRESCRIPCIÓN 3. LAS CARENCIAS DEL MÉTODO INTERPRETATIVO CONSISTENTE EN LA AVERIGUACIÓN DE LA NATURALEZA JURÍDICA DE LA PRESCRIPCIÓN 3.1. No existe una distinción radical entre Derecho penal y Derecho procesal penal 3.2. Los resultados obtenidos al aplicar la doctrina de la naturaleza de la cosa a una institución jurídica han sido predeterminados de antemano 3.3. No existe una distinción radical entre Parte General y Parte Especial del Código Penal 
4. LAS VENTAJAS DE UN PLANTEAMIENTO DISTINTO: LEGISLAR ATENDIENDO A LA PRESCRIPTIBILIDAD O POSIBILIDAD DE PRESCRIPCIÓN COMO CUALIDAD DE CADA DELITO DE LOS TIPIFICADOS EN EL CÓDIGO PENAL EN LUGAR DE ATENDER A LA PRESCRIPCIÓN COMO INSTITUCIÓN INELUDIBLE PARA TODOS LOS DELITOS.

\section{PLANTEAMIENTO DEL TEMA}

La prescripción del delito conlleva la imposibilidad de que el Estado enjuicie a sus responsables por razón del tiempo transcurrido desde su comisión. Se trata de una institución de larga tradición histórica, que se encontraba ya presente en la Grecia clásica, como se desprende de los discursos de DEMÓSTENES ${ }^{1}$ y de LISIAS $^{2}$.

No obstante, los distintos juristas que se han ocupado de pensar sobre la prescripción difieren a la hora de señalar su fundamento. Algunos lo han querido ver en la necesidad de seguridad jurídica, de modo que la prescripción vendría a poner fin a la situación de incertidumbre que produce la falta de castigo de un delito a medida que el tiempo va transcurriendo ${ }^{3}$. Otros, que constituyen hoy la posición mayorita-

1 De los Discursos Políticos de DEMÓSTENES se deduce que ya entonces la prescripción era conocida, pues cuando éste era acusado por Esquines, argüía en su defensa: "sin embargo, cuando era posible imponerme un castigo según las leyes, si había cometido una injusticia en la rendición de cuentas, en las denuncias, en otros procedimientos legales, lo dejaste pasar. En cambio, cuando soy inocente en todos los aspectos, por las leyes, por el tiempo transcurrido, por la prescripción, por haber sido juzgado muchas veces ya acerca de todos los asuntos, por no haber quedado convicto de ninguna injusticia contra vosotros, y cuando es lógico que la ciudad participe en más o menos grado de la gloria de unos actos sancionados por el pueblo ¿ahora me salen al paso?”. DEMÓSTENES, Discursos Políticos. Obras Maestras. Editorial Iberia, Barcelona, 1969, p. 349.

2 También del Discurso contra Agorato de LISIAS, en el que éste sostiene la imprescriptibilidad de los crímenes del primero, se desprende que ya en la Grecia clásica se conocía la prescripción del delito. LISIAS, Discursos, Discurso contra Agorato (Discurso 13), Introducciones, traducción y notas de José Luis Calvo Martínez, Biblioteca Clásica Gredos, Madrid, 1988.

Tradicionalmente, la doctrina jurídica ha considerado a la seguridad jurídica como uno de los principales fundamentos de la prescripción, al que parecía referirse QUINTANO tiempo antes de que este concepto fuese elevado a la categoría de principio constitucionalmente garantizado (art. 9.3 de la Constitución de 1978), "por el definitivo argumento de que hay que poner un término a todas las cosas". Ello no impedía, sin embargo, que el autor se mostrase partidario de fijar condiciones tendentes a evitar que la prescripción se convierta en una prima otorgada al criminal hábil. Cfr. A. QUINTANO RIPOLLÉS, Comentarios al Código Penal, Editorial Revista de Derecho Privado, Madrid, 1966, p. 444. Por su parte, GONZÁLEZ TAPIA estima que "desde el momento en que la prescripción se sustenta sobre la eficacia destructora del tiempo y ésta es una verdad irrefutable, son múltiples los aspectos vinculados al delito sobre los cuales puede apreciarse dicha influencia. Las pruebas desaparecen, la Justicia tardía ya no es Justicia, el sentido del castigo se desdibuja y, cómo no, parece indispensable poner un término a la posibilidad de ejercer el ius puniendi del Estado". M ${ }^{\mathrm{a}}$ I. GONZÁLEZ TAPIA, La prescripción en el Derecho penal, Dykinson, Madrid, 2003, p. 46. Recuerdan estas palabras a las de PRINS: "la sociedad después de un cierto tiempo de inactividad queda desarmada pues la instrucción de un delito, para ser seria y eficaz debe ser realizada después de la perpetración del acto; cuando el tiempo pasa, las pruebas se disipan, la memoria de los testigos falla, los recuerdos de la infracción se 
ria, al menos en España, entienden que la prescripción se fundamenta en la falta de necesidad de pena por razón del tiempo transcurrido desde la comisión del delito ${ }^{4}$. Estos dos argumentos principales, por lo general remezclados entre sí, han sido recogidos en mayor o menor medida por nuestra jurisprudencia, que no ha aclarado el asunto, si bien la verdadera polémica, más que al fundamento, se ha referido a la naturaleza jurídica de la prescripción. Al respecto, algunos autores -por lo general los que entienden que la prescripción se basa en la necesidad de seguridad jurídicahan considerado que se trata de una institución de naturaleza procesal. Así lo han defendido, entre otros, AGUILERA DE PAZ (con matices) ${ }^{5}$, QUINTANO RIPOLLÉS $^{6}$, o JIMÉNEZ DE ASÚA ${ }^{7}$, por citar algunos de los autores más importantes de nuestra literatura jurídica clásica. Entre los autores más recientes que han defendido esta tesis procesal, puede mencionarse a BANACLOCHE PALAO ${ }^{8}$ y a MEDINA CEPERO $^{9}$. Sin embargo, la corriente doctrinal actualmente mayoritaria en España es la de quienes afirman que la razón de ser de la prescripción es la desaparición de la necesidad de la pena por efecto del transcurso del tiempo desde que se cometió el delito, que conlleva el olvido del hecho, haciendo la pena innecesaria, por lo que la

borran, y al mismo tiempo que la utilidad de la persecución disminuye, los riesgos de error judicial aumentan". A. PRINS, Science pénale et Droit positif. Bruxelles-Paris, 1899, pp. 560-561, citado en L. MORILLAS CUEVA, voz "Prescripción del delito y de la pena", en Nueva Enciclopedia Jurídica, vol. XX, Editorial Francisco Seix, Barcelona, 1993, pp. 269-295 (274). En la doctrina española actual, MUÑOZ CONDE afirma que la prescripción es una "causa de extinción de la responsabilidad criminal fundada en la acción del tiempo sobre los acontecimientos humanos. Su fundamento radica, pues, más en razones de seguridad jurídica que en consideraciones de estricta Justicia material”. F. MUÑOZ CONDE-M. GARCÍA ARÁN, Derecho Penal, Parte General. $5^{\text {a }}$ edición. Tirant lo Blanch, Valencia, 2002, p. 420.

4 Pese a que el art. 25.2 de la vigente Constitución de 1978 declara que las penas privativas de libertad están orientadas a la reeducación y a la reinserción social, no puede obviarse su eterno componente retributivo. Y para hacer compatible la pena retributiva con la posibilidad de prescripción del delito, se hace necesario, como apunta GONZÁLEZ TAPIA, que se considere que el transcurso del tiempo anula, a su vez, la culpabilidad del sujeto (fundamentado en que la pena actúa sobre la mala voluntad del sujeto y ésta se debilita por el paso del tiempo) o que el tiempo destruye la relación psicológica entre el hecho y su autor, alternativa que no obstante, no ha sido planteada por la doctrina ni por la jurisprudencia, por lo que puede decirse, que el transcurso del tiempo no afecta al merecimiento, sino a la necesidad de pena. Cfr. $M^{\mathrm{a}}$ I. GONZÁLEZ TAPIA: La prescripción en el Derecho Penal, cit., p. 67.

Aunque ya aceptaba este autor, a comienzos del siglo XX que, en base al art. 2 LECrim, la prescripción debería también poder apreciarse de oficio. Cfr. E. AGUILERA DE PAZ, Comentarios a la Ley de Enjuiciamiento Criminal, Ed. Reus, Madrid, 1924, Tomo V, pp. 199 a 214.

6 A. QUINTANO RIPOLLÉS, Comentarios al Código Penal, cit., p. 465.

7 Para quien "La prescripción en materia penal es un instituto liberador, ora de la acción que nace del delito, bien de la acción que surge de la condena". Cfr. L. JIMÉNEZ DE ASÚA, Tratado de Derecho Penal, Tomo II (Filosofía y Ley penal), $4^{\text {a }}$ edición, Editorial Losada, Buenos Aires, 1964.

8 J. BANACLOCHE PALAO, "Algunas reflexiones críticas en torno a la prescripción penal”, Revista de derecho procesal, ISSN 0213-1137, № 2, 1997, pp. 281-320.

9 J. R. MEDINA CEPERO, El tratamiento procesal penal de la prescripción del delito, Dykinson, Madrid, 2001, p. 42. 
prescripción sería una institución de naturaleza material, siendo consecuencia de ello la posibilidad de su apreciación de oficio y la imposibilidad de aplicación retroactiva de las normas que modifiquen la regulación legal de esta figura en perjuicio del reo. Y así, en nuestra literatura jurídica, han defendido la naturaleza material de la prescripción del delito DEL TORO ${ }^{10}$, MORILLAS CUEVA ${ }^{11}$, COBO DEL ROSAL junto con VIVES ANTÓN ${ }^{12}$, MUÑOZ CONDE ${ }^{13}$ y MIR PUIG ${ }^{14}$ entre otros muchos.

En líneas generales, puede decirse que la concepción procesal de la prescripción exige su alegación a instancia de parte, permitiendo asimismo la modificación de los plazos de prescripción en perjuicio del reo después de cometido el delito. La concepción material, en cambio, permite la apreciación de la prescripción de oficio por el juez, e impide aplicar retroactivamente normas que aumentasen el plazo de prescripción del delito o lo declarasen imprescriptible. Para completar el panorama, y dado que la doble regulación de la prescripción en el Código sustantivo y en el procesal en España otorga argumentos siquiera parciales a los defensores de una y otra postura -sin perjuicio de que algunas soluciones que alcanzaría la concepción procesalista son inadmisibles, pues el art. 9.3 de la Constitución prohíbe la retroactividad de las normas penales en perjuicio del reo-, tampoco faltan autores que abogan por dejar abierta la cuestión, afirmando que la prescripción tiene una naturaleza mixta ${ }^{15}$.

Pero a pesar de lo extenso de la discusión en cuanto al fundamento y naturaleza de la prescripción, de las severas críticas que la institución recibió en otros tiempos ${ }^{16}$, y de que en el ámbito internacional, desde los Juicios de Núremberg, se viene impo-

10 A. DEL TORO MARZAL, Comentarios al Código Penal. Tomo I, Barcelona, 1978, p. 675.

11 L. MORILLAS CUEVA, Acerca de la prescripción de los delitos y las penas, Granada, Colección de Estudios Penales de la Universidad de Granada, núm. 3, 1980, p. 43.

12 M. COBO DEL ROSAL - T. S. VIVES ANTÓN, Derecho Penal, Parte General, Tirant lo Blanch, Valencia, 1991, p. 748.

13 F. MUÑOZ CONDE -M. GARCÍA ARÁN, Derecho Penal, Parte General $5^{\text {a }}$ edición, cit., p. 422.

14 S. MIR PUIG, Derecho penal, Parte General, ed. Reppertor, $9^{\mathrm{a}}$ edición, Barcelona, 2011, pp. 773 y ss.

15 Así, J. NÚÑEZ FERNÁNDEZ, Curso de Derecho Penal, Parte General, Dykinson, Madrid, 2011, pp. 1001 y ss.

En Alemania, pese a imperar la tesis procesalista, puede citarse a JECHECK, quien considera que la prescripción es una causa personal de anulación de la pena que, sin embargo, está configurada desde el punto de vista jurídico-procesal como un obstáculo procesal. H. H. JESCHECK, - T. WEIGEND, Tratado de Derecho Penal, Parte General, Traducción de Miguel Olmedo Cardenete,

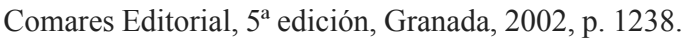

16 La Escuela positiva italiana se propuso modificar la esencia de la institución hasta tal punto que bien puede decirse, con PEDREIRA GONZÁLEZ, que manifestó una actitud contraria a la misma. Cfr. F. M. PEDREIRA GONZÁLEZ, La prescripción de los delitos y de las faltas. Doctrina y Jurisprudencia, editorial Centro de Estudios Ramón Areces, Madrid, 2004, pp. 72-73.

Fuera de Italia, pero en sintonía con la misma idea de defensa social, el belga PRINS, que aceptaba la prescripción del delito como institución procesal, criticaba no obstante la prescripción de la pena por considerar que "es la impunidad pura y simple, y la impunidad es un mal ejemplo para las masas. A. PRINS, Science pénale et Droit positif, cit., p. 562. Cfr. L. MORI- 
niendo la regla de la imprescriptibilidad de determinados crímenes cometidos por los poderes estatales o fácticos, o sus estructuras afines, bajo el simplista argumento de evitar su impunidad ${ }^{17}$, en los ámbitos jurídicos y académicos -al menos en los españoles- no se discute hoy en día sobre la oportunidad de suprimir la posibilidad de que los delitos puedan prescribir ${ }^{18}$. De ahí que en los últimos tiempos se hayan endurecido las condiciones para que la prescripción pueda operar, e incluso que se venga a señalar en el Código Penal la imprescriptibilidad de determinados delitos, como son los de terrorismo que hubieren causado la muerte de una persona, como se hizo mediante la Ley Orgánica 5/2010, de 22 de junio, de reforma del Código Penal ${ }^{19}$, sin que tampoco tal imprescriptibilidad hubiera sido previamente establecida en el plano de los tratados internacionales, lo que venía siendo habitual hasta la fecha.

Por otro lado, aunque en los ambientes académicos se ha discutido largamente sobre el fundamento y la naturaleza jurídica de la prescripción del delito, al no haber alcanzado tal debate resultados concluyentes, no ha tenido influencia en la regulación legal de la institución en los textos positivos. En España, la prescripción del delito aparece aún hoy regulada a la vez en el Código sustantivo y en el procesal, citándose como causa de extinción de la responsabilidad criminal en el art. 130.1. $6^{\mathrm{o}}$ del Código Penal -señalándose asimismo los plazos de prescripción en el art. 131 $\mathrm{CP}$ y la forma en que ésta opera en el art. $132 \mathrm{CP}$ - mientras que la Ley de Enjuiciamiento Criminal, por su parte, cita la prescripción del delito en su art. 666 como uno de los artículos de previo pronunciamiento que pueden alegarse antes del inicio del juicio oral y que, en caso de estimarse, conducirá al sobreseimiento de la causa, se-

LLAS CUEVA, voz "Prescripción del delito y de la pena", en Nueva Enciclopedia Jurídica, cit, pp. 269-295 (273).

17 Si bien se mira, todo delito está previsto para evitar que el acto quede impune, aunque las llamadas doctrinas de la lucha contra la impunidad surgen como reacción frente a los métodos empleados en el marco de la llamada justicia de transición (transitional justice) o, en otra terminología, la de superación del pasado (Vergangenheitsbewältigung) a través de diversos instrumentos jurídico-políticos y sociales tan variados como el número de países que han afrontado estos procesos, pero fundamentalmente basados en las llamadas "comisiones de verdad" y procedimientos penales. Cfr. J. M. SILVA SÁNCHEZ, "Nullum crimen sine poena? Sobre las doctrinas penales de la «lucha contra la impunidad» y del «derecho de la víctima al castigo del autor»", en Víctima, Prevención del Delito y Tratamiento del Delincuente, VV. AA., Comares, Granada, 2009, pp. 17-41.

18 Otra cosa es, como pone de manifiesto RAGUÉS I VALLÉS, la mala fama de que goza la prescripción entre la ciudadanía no entendida en leyes, a lo que sin duda contribuye la imagen con que suele aparecer en los medios de comunicación. R. RAGUÉS I VALLÉS, La prescripción penal: fundamento y aplicación, Atelier, Barcelona, 2004, p. 15.

19 Con esta reforma, además se elevó de tres a cinco años el plazo de prescripción de los delitos menos graves. En la propia Exposición de Motivos de la Ley Orgánica 5/2010 se alega que "La impunidad debida a la prescripción de ciertos delitos castigados con penas de no excesiva gravedad (estafas, delitos urbanísticos, por ejemplo, o algunos delitos contra la Administración Pública), cuyo descubrimiento e investigación pueden sin embargo resultar extremadamente complejos y dilatados, ha redundado en descrédito del sistema judicial y en directo perjuicio de las víctimas. En este sentido, se opta por elevar el plazo mínimo de prescripción de los delitos a cinco años, suprimiendo por tanto el plazo de tres años que hasta ahora regía para los que tienen señalada pena de prisión o inhabilitación inferior a tres años". 
gún dispone el art. 675 del mismo texto legal. Tal regulación dual, como señala MORILLAS CUEVA, lleva a la paradoja de que una causa extintiva de responsabilidad criminal y, por tanto, de carácter sustantivo, se toma por nuestro legislador en la Ley de Enjuiciamiento Criminal como presupuesto de procedibilidad ${ }^{20} \mathrm{y}$, de este modo, aunque cada texto se ocupa de regular un aspecto de la cuestión, las referencias en ambos a la prescripción sigue dando pie a poder atribuirle bien una naturaleza material o bien una naturaleza procesal, manteniendo así viva la polémica.

La discusión acerca de la naturaleza de la prescripción tuvo su punto álgido en Alemania, cuando se acercaba el 8 de mayo de 1965 (transcurridos 20 años tras la capitulación) y los crímenes cometidos por el régimen nazi estaban a punto de prescribir. La doctrina alemana se decantó entonces mayoritariamente por asignar a la institución una naturaleza procesal, aceptando la tesis defendida por el ex Canciller Adenauer, que permitía continuar con la persecución de los delitos cometidos y evitar su prescripción, al considerar que hasta el 1 de enero de 1950, fecha en que los tribunales alemanes comenzaron a funcionar normalmente, no podía considerarse que comenzara a correr el plazo de prescripción ${ }^{21}$, lo cual entronca con la concepción procesalista de la prescripción penal, a imagen y semejanza de la civil, que tiene como presupuesto la posibilidad de ejercicio de la acción por su titular. Posteriormente, la Novena Ley de reforma del Derecho penal alemán de 1969 aumentó el plazo de prescripción de la acción penal para aquellos crímenes castigados con la pena de privación de libertad a perpetuidad, dando efectos retroactivos a ese aumento para permitir que pudieran continuar persiguiéndose los crímenes de violencia más graves cometidos durante la época nacional-socialista ${ }^{22}$. De este modo, se admitía la postura expresada en el Seminario de Derecho Penal y Política Criminal de la Universidad de Hamburgo en un informe de 5 de febrero de 1965 en el semanario "Die Zeit", y que fue traducido y dado a conocer en España por GIMBERNAT ${ }^{23}$, en el que los juristas firmantes se mostraban favorables a la prolongación de los plazos que aún estuviesen corriendo, considerando por lo general que la prescripción es sólo un obstáculo a la persecución del delito creado por el legislador en base a consideraciones que no afectan a la necesidad de castigo del hecho. HASSEMER describe de la siguiente manera cómo se articuló la solución: "la prescripción es una institución de carácter procesal que no se refiere a la penalidad del delito, sino a la posibilidad de su persecución. Y la prohibición de retroactividad sólo se refiere a los presupuestos de la penalidad, pero no a la persecución del delito. Por tanto, de acuerdo con este

20 Cfr. L. MORILLAS CUEVA, Acerca de la prescripción de los delitos y las penas, cit., p. 40.

21 Cfr. E. GIMBERNAT ORDEIG, "La prolongación del plazo de prescripción para asesinato en la República Federal de Alemania (breve comentario y traducción de la toma de posición del Seminario de Derecho Penal de la Universidad de Hamburgo)", Anuario de Derecho Penal y Ciencias Penales, ISSN 0210-3001, Tomo 18, Fasc/Mes 1, 1965, págs. 216-222.

22 H. H. JESCHECK, "La reforma del Derecho penal alemán. Fundamentos, métodos y resultados", Anuario de Derecho Penal y Ciencias Penales, 1972, pp. 629-642.

23 Cfr. E. GIMBERNAT ORDEIG, "La prolongación del plazo de prescripción para asesinato en la República Federal de Alemania (breve comentario y traducción de la toma de posición del Seminario de Derecho Penal de la Universidad de Hamburgo)", cit. 
entendimiento, todo el mundo puede confiar en que la penalidad de un hecho se rija por la ley vigente en el momento en que se cometió; pero esto no será así cuando se trata de los plazos para su persecución: Éstos no están limitados por la prohibición de retroactividad, porque nadie puede esperar jurídicamente que no se persiga el delito que ha cometido porque hayan trascurrido los plazos de prescripción que había en ese momento, si mientras tanto esos plazos de prescripción han sido ampliados y se aplican retroactivamente. Esto no supone ninguna violación del principio de legalidad" 24 . No es de extrañar que esta solución, como el propio autor indica, pueda parecerle una muestra de rabulismo jurídico al ciudadano que cree en el Estado de Derecho (y que en el fondo no es más que el respeto del Estado a sus propias leyes). Como en otros tantos aspectos jurídicos y políticos, la institución de la prescripción se vio afectada por el cambio de paradigma supuso el denominado "Holocausto". No en vano, es del horror de la constatación de los crímenes cometidos por el régimen nacionalsocialista y de la condena moral al régimen político que los cometió de donde procede la noción de imprescriptibilidad forjada en el ámbito del Derecho penal internacional como medio para evitar la impunidad, cuyos fundamentos se remontan hoy a los Principios de Núremberg, en los que, aunque la concreta palabra "imprescriptibilidad" no se emplee expresamente, se señalaba, en el Principio II, que el hecho de que la ley interna no imponga una pena por un acto que constituya un crimen internacional, no exime a la persona que cometió el hecho de responsabilidad conforme al derecho internacional ${ }^{25}$.

\section{LA PRETENDIDA UTILIDAD DEL DEBATE SOBRE LA NATURA- LEZA JURÍDICA DE LA PRESCRIPCIÓN}

La posibilidad de que los delitos puedan prescribir es, como todo lo regulado en los Códigos Penales, una cuestión de marcado carácter político. El mayor reconocimiento de la posibilidad de prescripción se ha ligado tradicionalmente a sistemas de corte liberal, mientras que, por lo general, se considera que las trabas a que la prescripción opere son más propias de regímenes autoritarios ${ }^{26}$. A esta circunstancia

24 Cfr. W. HASSEMER, ¿Por qué castigar? Razones por las que merece la pena la pena. Traducción de Manuel Cancio Meliá y Francisco Muñoz Conde, Tirant lo Blanch, Valencia, 2016, pp. 127-128.

25 En el texto original, en inglés, "The fact that internal law does not impose a penalty for an act which constitutes a crime under international law does not relieve the person who committed the act from responsibility under international law". Principio II, Report of the International Law Commission covering its Second Session, 5 June - 29 July 1950, Document A/1316.

26 PEDREIRA GONZÁLEZ concluye en un interesante estudio acerca de la Historia de la prescripción de las infracciones penales que "la negación de la prescripción posee, al menos en gran medida, una raíz autoritaria, que justifica el menoscabo de los derechos y garantías individuales en favor de unos pretendidos intereses sociales y colectivos que se hallan al margen del individuo y no dudan en sacrificarlo si fuera preciso. Ciertamente, no es una casualidad que los retrocesos más notorios en materia de prescripción penal se encuentren estrechamente vinculados a sistemas esencialmente antiindividualistas y autoritarios, y que sus grandes avances hayan venido de la mano de la legislación revolucionaria francesa". F. M. PEDREIRA GONZÁLEZ, "Breve 
se une el hecho de que, en los textos positivos que regulan los requisitos y efectos de la prescripción, existen inevitables lagunas que el intérprete ha de llenar para integrar la norma y adaptarla a cada caso concreto. Ello ha propiciado que los juristas acudan a la averiguación de la "naturaleza jurídica" de la prescripción como método interpretativo, llegando a distintos resultados en orden a cuestiones tan trascendentes como las antes citadas: la necesidad de su alegación a instancia de parte o la posibilidad de aplicación retroactiva de normas que modifiquen la regulación. Resulta así que la cuestión no es meramente académica, sino que tiene y ha tenido una gran importancia práctica, sobre todo cuando la regulación positiva aplicada a crímenes de gran trascendencia dejaba lugar a diferentes interpretaciones, derivando unas en la prescripción y otras en el castigo del delito.

Frente a la anteriormente citada doctrina alemana que entiende la prescripción como una institución procesal y que fue creada ad hoc para impedir la impunidad de los crímenes del régimen nacionalsocialista, puede decirse que, en líneas generales, la concepción de la prescripción como una institución de naturaleza material propicia una mayor seguridad jurídica y es más garantista para el reo, al impedir que novedosas regulaciones legales se le apliquen retroactivamente y en su perjuicio. La concepción material respeta así la máxima de que es la norma vigente en el momento de comisión de los hechos la que determina su calificación y, en consecuencia, el plazo de prescripción del delito, siempre que en el momento del enjuiciamiento la norma no haya sido sustituida por otra más benévola.

La naturaleza procesal de la prescripción, en cambio y como ha quedado de manifiesto con el anterior ejemplo histórico, permite una mayor discrecionalidad del Estado para alterar las reglas del juego, pues la estimación o no de la prescripción dependerá, según esta concepción, de las normas procesales vigentes en el momento del enjuiciamiento, y no de las sustantivas vigentes en el momento de la comisión del delito. La concepción procesal de la prescripción también facilita que crímenes cometidos en situaciones políticas excepcionales, en las que las instituciones del Estado no funcionaban de forma normal, por encontrarse desbordadas o inoperativas, o incluso en situaciones en las que el propio Estado o sus estructuras afines fueron quienes cometieron o ampararon los crímenes, éstos puedan ser juzgados mucho tiempo después de su comisión, cuando las condiciones consideradas normales se hayan alcanzado o reestablecido.

En el ámbito del Derecho civil, donde lo que prima es la seguridad del tráfico jurídico, tal necesidad de seguridad jurídica es el fundamento principal de la prescripción ${ }^{27}$. Pero pese a lo defendido por muchos autores de forma inercial, debe descartarse tal fundamento de la prescripción en la esfera del Derecho penal, pues lo cierto es que desde un punto de vista neutral, como es el que ha de adoptar el juzga-

referencia a la Historia de la prescripción de las infracciones penales. Especial consideración de la problemática surgida en el Derecho romano a través de dos aportaciones fundamentales", Revista de Derecho UNED, núm. 2, 2007, pp. 435-444.

27 Cfr. M. ALBALADEJO GARCÍA, La prescripción extintiva, Madrid, Colegio de Registradores de la Propiedad, Mercantiles y Bienes Muebles de España, 2004, p. 19. 
dor (no desde el punto de vista subjetivo del delincuente que por lo general buscará su impunidad) tanta certeza y seguridad aporta que el delito prescriba como que no. Es más, se mire como se mire, lo que mayor certeza aporta es la imprescriptibilidad, que asegura que en todo caso el crimen podrá ser perseguido mientras su autor viva. Fundar la posibilidad de prescripción del delito en la necesidad de certeza sólo sirve para poner en un plano de igualdad al delincuente y al Estado que debe castigarlo. Esa igualdad de partes, propia del Derecho civil, de carácter privado y fundada en la siquiera pretendida equivalencia de las contraprestaciones objeto de las obligaciones civiles, es inadmisible en el Derecho penal, donde ha de tenerse presente que el Estado se encuentra en una situación legítima y el delincuente (sin perjuicio de que su culpabilidad haya de ser probada tras el debido proceso en que se respete la garantía procesal de la presunción de su inocencia) en una situación ilegítima. Objetivamente, es por tanto la falta de la necesidad de pena, por haber transcurrido un tiempo más o menos largo desde la comisión del delito, lo que determina que tal castigo impuesto por el Estado no vaya a poder cumplir ya con sus fines de prevención general o especial, y en consecuencia que se permita la posibilidad de prescripción del delito. Y, en sentido contrario, cuando se trata de crímenes de mayor gravedad, que no pueden ser olvidados -o se considera que no deberían serlo- o simplemente respecto de los que exista un interés político manifiesto en que puedan ser castigados con independencia del tiempo transcurrido, la necesidad subsistente de imponer una pena-ya se funde ésta en una necesidad real sentida por la población o en una decisión meramente impuesta por el poder-, será lo que justifique la imprescriptibilidad.

Claro que, ante un hecho delictivo concreto, cometido hace ya tiempo, atendiendo a diversos factores tales como el daño causado, las posibilidades de reiteración delictiva o la alarma social suscitada, entre otros posibles, quien los busque, siempre encontrará argumentos tanto como para afirmar que la pena es aún necesaria como para afirmar que ya no lo es. Si bien se piensa, transcurrido un tiempo más o menos largo en relación con la experiencia vital humana, desde la comisión de un delito, la necesidad o no de imponer una pena en el caso concreto, la naturaleza jurídica de la prescripción y el resultado final consistente en castigar o no pueden considerarse tres elementos de una misma ecuación en la que la fijación de uno de estos factores como indiscutible (por lo general el castigar o no, decidido en las más ocasiones de antemano y atendiendo a criterios políticos o metajurídicos) determina los otros dos. El resultado se presentará, así, como el fruto de un razonamiento lógico-deductivo puro y desinteresado, cuando lo cierto es que las variables que han determinado ese resultado habían sido previamente escogidas, persiguiendo un concreto interés. Y es aquí donde juega su papel determinante el concepto de "naturaleza jurídica de la prescripción", sirviendo de cobertura a la decisión tomada.

Sin embargo, como puede comprobarse, el método interpretativo consistente en averiguar esa pretendida "naturaleza jurídica" de la prescripción tampoco ha arrojado resultados concluyentes, lo que ha determinado que, tanto en el extranjero como en España, continúen existiendo posturas doctrinales enfrentadas. En nuestro país, aunque hoy en día se acepta mayoritariamente la tesis de la naturaleza material, como se ha indicado, subsiste no obstante cierta confusión, a la que ha contribuido 
sin duda la actividad del legislador histórico, que ha cambiado de criterio en varias ocasiones desde los inicios de nuestro Derecho penal codificado ${ }^{28}$, $\sin$ que haya ayudado a aclarar la cuestión la jurisprudencia oscilante del Tribunal Supremo ${ }^{29}$, a la que hay que sumar, tras la aprobación de la Constitución de 1978, la doctrina del Tribunal Constitucional, que desde su Sentencia núm. 63/2005, de 14 de marzo, también se ha arrogado competencia para pronunciarse sobre la materia, afirmando que la prescripción penal "encuentra también fundamento en principios y valores constitucionales, pues toma en consideración la función de la pena y la situación del presunto inculpado, su derecho a que no se dilate indebidamente la situación que supone la virtual amenaza de una sanción penal" ${ }^{30}$. Pero, sobre todo, ha contribuido a la confusión la existencia de la doble regulación de la materia en el Código Penal y en la Ley de Enjuiciamiento Criminal, aún hoy persistente, que obedece tanto a la falta de una depurada técnica legislativa en la época en que se promulgaron los primeros códigos como a la influencia de la figura de la prescripción civil y al entendimiento general del proceso penal mediante la aplicación de figuras civiles, que sin embargo, como se ha indicado, tienen un fundamento distinto.

\section{LAS CARENCIAS DEL MÉTODO INTERPRETATIVO CONSIS- TENTE EN LA AVERIGUACIÓN DE LA NATURALEZA JURÍDICA DE LA PRESCRIPCIÓN}

Los vaivenes que ha experimentado la legislación, y con ella la jurisprudencia y la doctrina científica acerca de la naturaleza jurídica de la prescripción penal, ponen de manifiesto lo inútil de acudir al concepto de la "naturaleza jurídica" para

28 Si los primeros Códigos penales, desde el de 1822, recogían una regulación de la institución en clave procesal, el de 1932 supuso un gran cambio en esta materia, pues a partir de éste el Código Penal viene aceptando una concepción material de la prescripción que llega hasta nuestros días, sin perjuicio de que en la Ley de Enjuiciamiento Criminal, desde 1882, la prescripción se conciba como un mero obstáculo procesal a alegar como artículo de previo pronunciamiento.

29 Merece destacarse la Sentencia de 30 de noviembre de 1963 (RJ 1963, 4790), a partir de la cual el Tribunal Supremo consideró que la prescripción tenía una naturaleza material y no procesal como hasta entonces. Aunque se sucederían luego en el tiempo distintos vaivenes jurisprudenciales que laboriosamente recopila el C. REY GONZÁLEZ, en La prescripción de la infracción penal en el Código de 1995, Marcial Pons, $2^{\text {a }}$ edición de 1999, pp. 32 y ss.

30 Tribunal Constitucional, Sentencia 63/2005, de 14 de marzo (RTC 2005, 63). Las diferencias de interpretación acerca de qué actos procesales tienen la eficacia de interrumpir la prescripción a raíz de esta sentencia llegaron a originar un serio conflicto entre el Tribunal Constitucional y el Tribunal Supremo, habiéndose intentado zanjar la cuestión jurídica mediante la reforma del Código Penal operada por la Ley Orgánica 5/2010 que ha dado una nueva redacción al art. 132.2 CP. Con anterioridad a dicha Sentencia, el Tribunal Constitucional venía entendiendo que la prescripción era una cuestión de mera legalidad que correspondía decidir a los tribunales ordinarios y carecía de relevancia constitucional. Así en Sentencias del Tribunal Constitucional 152/1987 de 7 de octubre (RTC 1987, 152); 255/1988 de 21 de diciembre; 83/1989 de 10 de mayo (RTC 1989, 83); 12/1991 de 28 de enero (RTC 1991, 12); 223/1991 de 25 de noviembre (RTC 1991, 223); 150/1993 de 3 de mayo, entre otras muchas y Autos del Tribunal Constitucional 944/1989 (RTC 1989, 944 auto), 112/1987 (RTC 1987, 112 auto) y 340/2004 (RTC 2004, 340 auto). 
interpretar las normas que la regulan. Además, debe destacarse que, por lo general, no se acude a este concepto ante la imposibilidad de llegar a resultados satisfactorios mediante la aplicación del resto de métodos interpretativos conocidos ${ }^{31}$, sino más bien con la finalidad de enmascarar o cuanto menos justificar las verdaderas razones políticas de la decisión adoptada. Y es que llama la atención, en primer lugar, que no todos los conceptos ni instituciones jurídicas hayan suscitado tal debate sobre su "naturaleza" para explicar su fundamento o la forma en que despliegan sus efectos.

LOIS ESTÉVEZ, en su estudio sobre el concepto de "naturaleza jurídica"32, explica que "el término «naturaleza» es de uso constante en la Filosofía aristotélicoescolástica y en Teología. Resulta, pues, de franca verosimilitud que los filósofos lo hayan exportado al campo jurídico. El mismo hecho de que los juristas lo hayan utilizado constantemente sin recurrir a clarificaciones complementarias parece probar, por sí mismo, que fuera como valor entendido para todos. Esto, por lo menos, no permite abrigar serias dudas". Pero como observa nuestro autor, "lo que ya es problemático, en cambio, es por qué hayan tenido que echar mano a esa noción los juristas". Cabe añadir que el debate en torno a la naturaleza jurídica de la prescripción tampoco ha sido todo lo profundo que en un principio cabría esperar a la vista de la grandilocuencia de la expresión y de las cuestiones filosóficas que la misma evoca ${ }^{33}$, pues la discusión doctrinal se ha limitado a tratar de determinar si se trata de una materia de naturaleza sustantiva o procesal, pero esto no dice nada sobre la verdadera esencia de la prescripción, esto es, cuáles son los efectos que produce y de qué forma, pues la cualidad de ser una institución material o procesal también podría predicarse de cualquier otra figura jurídica. Por otro lado, el principal obstáculo que se ha encontrado para otorgar validez a los resultados obtenidos de la aplicación de la doctrina de la naturaleza de la cosa a la prescripción del delito es que la concepción vigente del ordenamiento jurídico como un sistema de normas ordenado jerárquicamente no permite asignar a la prescripción una determinada naturaleza de la que se derive todo un elenco de consecuencias en principio deducidas lógicamente pero que, sin embargo, contradigan lo dispuesto en normas de rango jerárquico superior. Así, en España, la correcta aplicación del principio de irretroactividad de las disposiciones

31 Desde SAVIGNY, se distinguen cuatro medios de interpretación, que aún hoy se utilizan: el gramatical, el lógico, el histórico y el sistemático. Cfr. K. LARENZ, Metodología de la Ciencia del Derecho, Ariel Derecho, Barcelona, $4^{\circ}$ impresión de 2010, p. 316. Con IHERING y la jurisprudencia de los intereses se añadió el aspecto teleológico, esto es, la búsqueda de la finalidad de la ley. JIMÉNEZ DE ASÚA explica cómo a través del tiempo se han mantenido dos posiciones contrapuestas para esclarecer la significación de los artículos de una ley: la de la llamada Escuela Exegética, que propugna una interpretación filológica-histórica, y la más moderna, que sigue un método lógico-sistemático y que hoy adquiere su mejor forma con la interpretación teleológica. L. JIMÉNEZ DE ASÚA, Tratado de Derecho Penal, Tomo II (Filosofía y Ley penal), cit., p. 413.

32 J. LOIS ESTÉVEZ, "Sobre el concepto de «naturaleza jurídica»", Anuario de Filosofía del Derecho, ISSN 0518-0872, No 4, 1956, pp. 159-182.

33 Una visión esquemática de los principales puntos de vista y problemas que suscita la cuestión de la "naturaleza jurídica" o "naturaleza de la cosa" se encuentra en F. PUY MUÑOZ, "El Derecho y la naturaleza de las cosas", Anuario de Filosofía del Derecho, ISSN 0518-0872, No 12, 1966, pp. 75-94. 
desfavorables, constitucionalmente consagrado en el art. 9.3 de la Constitución de 1978, no permite la aplicación retroactiva de normas tales como las que amplíen los plazos de prescripción o declaren un delito imprescriptible si con ello se perjudica al reo que delinquió cuando estaba vigente otra norma penal sustantiva cuya aplicación le resulte más favorable.

Lo dicho invalida ya muchos de los resultados a los que puede llegarse mediante la aplicación de la doctrina de la "naturaleza jurídica" a la prescripción del delito. Sin perjuicio de ello, cabe no obstante dilucidar si son o no acertados los presupuestos sobre los que se apoyan las tesis acerca de la posibilidad de atribuir a la prescripción del delito una naturaleza jurídica sustantiva o procesal, al haber casos en los que puede llegarse a soluciones no contradictorias con normas de rango superior.

El primero y fundamental de tales presupuestos es el punto de partida consistente en la pretendida existencia de una distinción radical entre Derecho penal y Derecho procesal penal, lo que permitiría ubicar la figura de la prescripción del delito en uno solo de esos dos campos, para luego aplicarle la generalidad de principios y reglas que disciplinan tal rama del Derecho.

El segundo, en íntima conexión con el anterior, es la creencia de que la doctrina de la "naturaleza de la cosa", aplicada a una institución jurídica, persiguiendo así su encasillamiento en el campo sustantivo o procesal, puede conducir a resultados válidos que sean consecuencias lógicas de la propia estructura objetiva del sistema jurídico, sin que el intérprete influya en el resultado, predeterminándolo.

Finalmente, y del mismo modo que debe cuestionarse si existe o no una división radical entre Derecho sustantivo y Derecho procesal, cabe también preguntarse si existe una distinción relevante a estos efectos, dentro del ámbito del Derecho penal codificado, entre la Parte General y la Parte Especial del Código Penal, pues es de esta forma codificada como se presentan las normas penales en nuestra cultura jurídica. Tras ello, puede determinarse si la prescripción puede ubicarse de modo exclusivo en la Parte General del Derecho penal, o si por el contrario, como cabe ya adelantar, lo más adecuado es considerar que la posibilidad o no de prescripción no es más que una cualidad propia de cada uno de los delitos de los señalados en el Código y que afecta a su punibilidad, pudiendo el legislador someterla a distintos presupuestos y requisitos para que opere en relación con cada uno de los tipos delictivos de la Parte Especial.

\subsection{No existe una distinción radical entre Derecho penal y Derecho proce- sal penal}

Pese a la importancia interpretativa que tradicionalmente se ha dado a la ubicación de la prescripción en un determinado texto legal -bien sea el Código Penal o bien la Ley de Enjuiciamiento Criminal-, ya a principios de los años 50 del siglo pasado, GÓMEZ ORBANEJA advertía que "la colocación de una norma en uno u otro cuerpo legal es indiferente para determinar su naturaleza; lo que importa es su contenido y finalidad. Sacar algo del Código Penal no es lo mismo que sacarlo del 
Derecho Penal; y a la inversa, no basta incluir en ese Código un precepto referente al proceso para desposeerle de su carácter verdadero" 34 .

Para que el Derecho penal alcance su finalidad - que en definitiva no es otra que la imposición de una pena, con los fines que quieran asignársele, ya sean de prevención general, especial o incluso de mera retribución sujeta a criterios de justicia-, es necesario que el Derecho sustantivo y el procesal confluyan, pues jurídicamente no cabe la imposición de una pena sin seguir un proceso judicial. El problema de ubicar la prescripción del delito en el campo sustantivo o en el procesal se remonta, en nuestro Derecho, a los inicios de la legislación codificada, con la doble regulación en el Código Penal y en la Ley de Enjuiciamiento Criminal.

La primera regulación sistemática de la prescripción penal en la Codificación española se encuentra en el primer Código Penal español, de 1822, que se refería a la prescripción de los delitos en su Capítulo XI del Título Preliminar, bajo la rúbrica "De la prescripción de los delitos y culpas", que comprendía los arts. 171 a 178. El Código Penal de 1870 pretendió adaptar el texto de 1850 a las exigencias de la Constitución de 1869 surgida de la revolución liberal de 1868 y, como hiciera el Código de 1822, incluyó en su articulado la regulación de la prescripción del delito, que se había suprimido en el anterior de 1848, sin esperar a que se aprobara una Ley de Enjuiciamiento Criminal, que no vería la luz hasta 1882. El Código de 1870 establecía una regulación fundada en la negligencia en la persecución, no del delito (pues si éste está oculto la ley no impedía que fuesen averiguadas en cualquier momento sus circunstancias) sino del propio delincuente, lo que otorgaba a éste un contraderecho que por ello podría alegar (a instancia de parte) para impedir la celebración del juicio oral. Tal concepción de la institución, claramente iusprivatista, tuvo su reflejo en la Ley de Enjuiciamiento Criminal de 1882, que, sin definir la prescripción del delito, reconoció en su art. 666 -aún vigente y sin que se haya modificado desde entonces el precepto-, la posibilidad de alegarla a instancia de parte como uno los artículos de previo pronunciamiento. Si se estima la prescripción, en virtud de lo dispuesto en el art. 675 LECrim, ello supone la imposibilidad de abrir el juicio oral, pues deberá dictarse auto de sobreseimiento que habrá de fundarse en el motivo $3^{\circ}$ del art. 637, que señala que "Procederá el sobreseimiento libre: (...) Cuando aparezcan exentos de responsabilidad criminal los procesados como autores, cómplices o encubridores" 35 .

La discusión doctrinal acerca de la naturaleza material o procesal ha llegado hasta nuestros días, habiendo tenido su punto álgido en el Derecho alemán, donde, como se ha apuntado, se enfatizó en la importancia de distinguir entre Derecho sustantivo y procesal a efectos de ubicar la prescripción del delito en una de estas dos ramas $^{36}$-decantándose finalmente la balanza por la concepción procesal de la insti-

34 E. GÓMEZ ORBANEJA, Comentarios a la Ley de Enjuiciamiento Criminal, Tomo I, Barcelona, Bosch, 1951, p. 39.

35 Solución que explica V. GIMENO SENDRA, Manual de Derecho Procesal Penal, Universidad Nacional de Educación a Distancia, $3^{\text {a }}$ edición, 2013, p. 406.

36 En este sentido, W. HASSEMER, "La medida de la Constitución”, en Constitución, derechos fundamentales y sistema penal, Tomo I, Semblanzas y estudios con motivo del setenta aniversario del Profesor Tomás Salvador Vives Antón, J. C. Carbonel Mateu, J.L. González Cussac, 
tución, como explicara GIMBERNAT ${ }^{37}$ - para evitar que los crímenes nazis pudieran prescribir. Pero toda solución en orden a determinar un concepto de la prescripción del delito que permita a la ciencia jurídica avanzar, debería partir, como señala GÓMEZ COLOMER, de la premisa de que Derecho Penal no puede aplicarse fuera del proceso penal, por exigencias derivadas del principio de necesidad, verdadera columna vertebral de este proceso; de ahí la interrelación e interactividad tan esenciales entre ambas ramas del Derecho, que hacen absolutamente imposible entender el proceso penal sin los conocimientos básicos del Derecho Penal, y a la inversa ${ }^{38}$. En este mismo sentido, recuerda COBO DEL ROSAL que el Derecho procesal penal es "un Derecho de acompañamiento necesario: El Derecho penal no es más que una tabla de valores y de sanciones que sólo puede adquirir concreción a través del Derecho procesal penal". Y por eso el Derecho procesal tiene un carácter secundario, de modo que no goza más que de una "cierta y limitada autonomía, que viene derivada del sentido de los textos que disciplinan el proceso penal". En palabras de BELING, traídas por COBO DEL ROSAL, "el Derecho penal determina sólo la pena que en cada caso corresponde", y el Derecho procesal penal, las actividades humanas que han de realizarse para la "inflicción de la pena en su caso" 39.

La solución del problema de la retroactividad de las nuevas normas en materia de prescripción, como señalan COBO DEL ROSAL y VIVES ANTÓN, no depende por tanto de su naturaleza material o formal, sino del carácter absoluto o relativo que se otorgue, en materia procesal, a la regla tempus regit actum, que en nuestro Derecho positivo ha de tener necesariamente un carácter relativo, pues como los propios autores indican, su aplicación indiscriminada y absoluta produciría consecuencias inconstitucionales ${ }^{40}$. Es por ello por lo que también otros autores actuales, como PEDREIRA GONZÁLEZ, relativizan la importancia de la cuestión de la naturaleza jurídica de la prescripción -en relación con los términos en que el debate nos ha venido planteado-, pues las consecuencias que derivan de las soluciones que pueden alcanzarse mediante este método pueden resultar contrarias a la Constitución, norma de rango superior del ordenamiento jurídico, que en su art. 9.3 garantiza la irretroactividad de las disposiciones sancionadoras no favorables o restrictivas de derechos individuales ${ }^{41}$.

E. Orts Berenguer (dirs.) M. L. Cuerda Arnau (coordinadora), Tirant lo Blanch, Valencia, 2009, pp. 975 y ss.; H. H. JESCHECK - T. WEIGEND, Tratado de Derecho Penal, Parte General, cit., pp. 982-983.

37 Cfr. E. GIMBERNAT ORDEIG, "La prolongación del plazo de prescripción para asesinato en la República Federal de Alemania (breve comentario y traducción de la toma de posición del Seminario de Derecho Penal de la Universidad de Hamburgo)", cit.

38 J. L. GÓMEZ COLOMER, Constitución y proceso penal, Tecnos, Madrid, 1996, p. 16.

39 Cfr. M. COBO DEL ROSAL, Tratado de Derecho procesal penal español, Centro de Estudios Superiores de Especialidades Jurídicas, Madrid, 2008, pp. 39 y 40, citando a su vez a GIMENO SENDRA y MORENO CATENA.

40 M. COBO DEL ROSAL -T. S. VIVES ANTÓN, Derecho Penal, Parte General, cit., p. 162.

${ }^{41}$ F. M. PEDREIRA GONZÁLEZ, "La prescripción de las infracciones penales tras la reforma introducida por la Ley Orgánica 15/2003, de 25 de noviembre”, en La Ley, año XXVI, núm. 6249 , martes 10 de mayo de 2005, pp. 1-10. 


\subsection{Los resultados obtenidos al aplicar la doctrina de la naturaleza de la cosa a una institución jurídica han sido predeterminados de antemano}

Si la importancia de un concepto que en principio parece evocar verdades indiscutibles, como es el de la "naturaleza jurídica", debe ser relativizado al tratar la cuestión de la prescripción del delito porque su aplicación irreflexiva arroja soluciones contrarias al propio ordenamiento jurídico, concebido hoy como un sistema de normas interrelacionadas, resulta corroborado lo advertido en su día por el Abogado y Filósofo del Derecho argentino CARRIÓ: "las afanosas pesquisas de los juristas por «descubrir» la naturaleza jurídica de tal o cual institución o relación están de antemano y de forma irremisible destinadas al fracaso. Entre otras razones porque lo que se busca, tal como se lo busca, no existe. Las conclusiones que alcanza son, pues, claras y rotundas: no es útil hablar de la naturaleza jurídica; las discusiones sobre supuestas naturalezas jurídicas, en cuanto los contenedores no se hacen claramente cargo de lo que están buscando, ni de la verdadera causa de su desacuerdo, son a la vez estériles e insolubles" ${ }^{42}$.

En palabras de otro jurista argentino que también se interesó por el concepto de "naturaleza", GARZÓN VALDÉS, los conceptos e instituciones jurídicas no serían más que una de las categorías de $\operatorname{cosas}^{43}$ a las que tradicionalmente se ha aplicado la doctrina de la naturaleza de la cosa como fuente del derecho para, partiendo de la propia naturaleza del objeto, tratar de obtener respuestas jurídicamente válidas, esto es, como concepto del que emanan implicaciones del deber ser, de modo que se atribuye al ser un poder normativo. La concepción, como refiere este autor, es antigua: estaba ya presente en la concepción heracliteana de diké como aquello que corresponde al ser, y fue recogida y actualizada por la filosofía aristotélico-tomista y el idealismo objetivo de HEGEL, SCHELLING y SCHELEIERMACHE ${ }^{44}$.

Esa emanación de implicaciones normativas, de deber ser, de algo que simplemente es, a la que alude el concepto de naturaleza jurídica según apunta GARZÓN VALDÉS, fue señalada también por BASTIDE y BOBBIO, citados por PUY MU$\mathrm{NOZ}^{45}$, quien por su parte afirma que la naturaleza de la cosa es una totalización falsa por la que se identifica lo sociológicamente jurídico-moral con lo normal, y lo normal con lo natural; o sea, una totalización por la que sucesivamente se va identificando, en saltos ilógicos, lo que ocurre con frecuencia, con lo que ocurre normalmente, con lo que ocurre según norma, con lo que ocurre porque tiene que ocurrir, con lo que ocurre porque debe de ocurrir. En definitiva, la naturaleza de la cosa sería el intento infructuoso de extraer el deber-ser del ser.

${ }^{42}$ G. R. CARRIÓ, Notas sobre Derecho y lenguaje, Ed. Abeledo-Perrot, Buenos Aires, 1965, pp. 101 y ss.

43 Las demás categorías de cosas a las que tradicionalmente se ha aplicado la doctrina de la naturaleza de la cosa como fuente del derecho serían, según GARZÓN VALDÉS, el hombre y su realidad psicosomática, los objetos físicos del mundo, una entidad metafísica a priori, y las relaciones del hombre con sus semejantes y con los objetos mencionados. Cfr. E. GARZÓN VALDÉS, "La naturaleza de la cosa", cit.

44 Cfr. E. GARZÓN VALDÉS, "La naturaleza de la cosa”, cit.

45 Cfr. F. PUY MUÑOZ, "El Derecho y la naturaleza de las cosas", cit. 
GARZÓN VALDÉS viene a sintetizar los peligros de aplicar la doctrina de la naturaleza de la cosa a una institución jurídica, esto es, al pretender derivar una norma de deber ser partiendo de la naturaleza de las cosas. Así, al actuar de esa manera, puede suceder lo siguiente:

a) que se cometa un salto deductivo, en cuyo caso no hay inferencia alguna;

b) que se razone entimemáticamente e introduzcamos en las cosas el sentido o valor que queramos extraer de las mismas, que es lo que hace el legislador cuando atribuye relevancia jurídica a ciertas notas distintivas de las cosas del mundo exterior (es el sentido de la naturaleza de las cosas según RAD$\left.\mathrm{BRUCH}^{46}\right)$;

c) que creamos estar describiendo la naturaleza de una cosa (institución) y derivando consecuencias del deber ser cuando en realidad estamos tan sólo glosando normas de deber ser de un ordenamiento positivo o iusnaturalis$\mathrm{ta}^{47}$.

Por eso, recuerda GARZÓN VALDÉS que del concepto de "naturaleza" se ha llegado a afirmar, como hiciera ERNST BEKKER, que "como no obliga a pensar en serio a menudo es utilizada como un sustituto del pensamiento". Y así, cuestionando detenidamente lo que sucede con la llamada naturaleza de las instituciones o conceptos jurídicos, observa el filósofo argentino que la mención de la palabra naturaleza parecería indicar que detrás de ellos "habría alguna realidad que el jurista tendría que precisar y descubrir”, pero como BULYGIN ya demostró con suficiente claridad, "en estas palabras no hay ente alguno y que se trata sólo de vocablos útiles para designar una serie de hechos condicionantes descritos por una norma y las consecuencias jurídicas prescriptas por aquéllas" ${ }^{48}$. GARZÓN VALDÉS concluye así en su estudio que la utilización del concepto "naturaleza de la cosa", por su ambigüedad,

46 Cabe mencionar aquí que para RADBRUCH, "Los preceptos del deber ser, los juicios de valor, las estimaciones no pueden fundamentarse inductivamente sobre posiciones de ser, sino deductivamente sobre preceptos de especie semejante." Por eso, cuando un jurista falla sobre la naturaleza de las cosas, la contemplación de la idea en la materia es un caso feliz de intuición, pero no un método de conocimiento, pues "Para el conocimiento metódico queda en firme que los preceptos del deber ser sólo pueden derivarse deductivamente de otros preceptos del deber ser y no pueden fundamentarse inductivamente en hechos de ser". Y por ello, "los supremos preceptos del deber ser son indemostrables, axiomáticos, no susceptibles de conocimiento, sino tan sólo de creencia". Cfr. G. RADBRUCH, Filosofía del Derecho, Editorial Revista de Derecho Privado, Madrid, 1944, pp. 14-17.

47 Cfr. GARZÓN VALDÉS, ERNESTO: «La naturaleza de la cosa», cit.

48 En E. BULYGIN, La naturaleza jurídica de la letra de cambio, Buenos Aires, 1963. GARZÓN VALDÉS propone como ejemplos la propiedad y el contrato, pero no existe inconveniente alguno en aplicar los mismos razonamientos a otra institución jurídica como la prescripción del delito. Cfr. GARZÓN VALDÉS, ERNESTO: «La naturaleza de la cosa», cit.

PEDREIRA, sin embargo, afirma en su estudio sobre la prescripción de los delitos que en el ámbito del Derecho, siempre que se aborda el estudio de una institución resulta conveniente preguntarse por su naturaleza jurídica, pues ello posibilita un mejor conocimiento e interpretación de la misma, además de permitir su adecuación en el sistema jurídico. F. M. PEDREIRA GONZÁLEZ, La prescripción de los delitos y de las faltas. Doctrina y Jurisprudencia, cit., p. 81. 
sirve más para confundir que para aclarar las ideas, hasta el punto de que hablar de la naturaleza de ciertas cosas, como son las instituciones y conceptos jurídicos, carece de sentido y en otros casos es mejor mencionar directamente cuáles son las características que se tienen en cuenta en el razonamiento de que se trata y evitar el uso de la expresión ${ }^{49}$.

En su obra $T \hat{u}-t \hat{u}^{50}$, el danés ALF ROSS, siguiendo un relato de EIDAN, explica que los miembros de una tribu primitiva del Pacífico designaban con la palabra $t \hat{u}$-t $\hat{u}$ lo que surge cuando alguno de sus miembros viola un determinado tabú. "Por ejemplo si un hombre se encuentra con su suegra, o mata un determinado animal tótem, o si alguno ingiere comida preparada para el jefe". No sólo es que eso fuera $t \hat{u}$ - $t \hat{u}$, sino que además, los demás miembros de la tribu decían que quien comete la infracción se pone $t \hat{u}$-t $\hat{u}$, concibiendo con tal expresión una especie de fuerza o lacra peligrosa que recae sobre el culpable y amenaza a toda la comunidad con el desastre, y por esta razón una persona que esté $t \hat{u}-t \hat{u}$ tiene que ser sometida a una ceremonia especial. Claro que como explica ROSS, tĥu-tû no es nada, sólo fruto de la superstición, pero la palabra cumple en el lenguaje la esencial función de prescribir y describir, o para ser más explícito, expresar órdenes o reglas, y hacer afirmaciones sobre hechos. Pues bien, existen palabras que en nuestros idiomas cumplen una función similar. "«Propiedad», «crédito» y otras palabras, cuando son usadas en el lenguaje jurídico, tienen la misma función que la palabra $t \hat{u}$-t $\hat{u}$; son palabras sin significado, sin referencia semántica alguna, y sólo sirven a un propósito, como una técnica de presentación". Estos términos vendrían en definitiva a cumplir una función de eslabón que enlaza con una tradición ligada al lenguaje y al poder que éste tiene sobre el pensamiento. Pues bien, resulta claro que lo mismo sucede con el concepto de "naturaleza jurídica" y, aunque no puede despreciarse absolutamente, toda vez que cumple una función lingüística, debe tenerse presente que sólo sirve para desempeñar una función retórica, a modo de presentación de las características de la institución o figura que se pretende describir, como es el caso de la prescripción del delito. Pero esas características deben ser luego definidas con precisión, porque las cualidades de la figura y la forma en que ésta interactúa con el resto de proposiciones del ordenamiento jurídico no emanan mágicamente de la "naturaleza" que se le asigne, sino de las previsiones establecidas por el legislador -que quizás ni siquiera tuvo en cuenta todas las implicaciones que podrían derivarse de una determinada "naturaleza"- y, en su caso, del sentido que a tales previsiones atribuya el intérprete en base a los distintos métodos de interpretación jurídica generalmente aceptados, pero sin que en ningún caso de la propia cosa emanen cualidades que obliguen al intérprete a decantarse por una determinada interpretación contraria a la lógica interna del ordenamiento y a las finalidades sociales que éste pretende.

La Historia pone de manifiesto que cuando se ha actuado de otro modo, dejando que sea la propia "naturaleza de la cosa" la que guíe la interpretación, lo que se ha

49 Cfr. E. GARZÓN VALDÉS, "La naturaleza de la cosa", cit.

50 Cfr. A. ROSS, Tû-tû, Traducción de Gerardo Rubén Carrió, Colección Nueva Teoría, Abeledo-Perrot, Buenos Aires, 1961, pp. 23-24. 
hecho ha sido enmascarar las verdaderas razones políticas que determinan la decisión del intérprete de la norma pues, como afirma HABA MÜLLER, "Cuando para argumentar en favor de la decisión $Y$ se sostiene que es la que corresponde a la naturaleza jurídica $\mathrm{X}$, entendida esta de la manera $\mathrm{A}$, o al rechazar la solución $\mathrm{Z}$ por no corresponder a dicha naturaleza, quien realmente decide es aquél a quien se le reconoce la autoridad para re-conocer cuál sea la verdadera naturaleza del instituto jurídico invocado (en este caso: ese jurista que dictamina A) y cuáles son las verdaderas consecuencias que se siguen de ahí (en este caso: $\mathrm{Y}$, a juicio de dicho jurista)" ${ }^{51}$.

\subsection{No existe una distinción radical entre Parte General y Parte Especial del Código Penal}

La prescripción del delito no es una institución irreductible, sino el resultado de la condensación de distintas reglas jurídicas homogéneas. LOIS ESTÉVEZ, en su artículo "Sobre el concepto de «naturaleza jurídica»" publicado en el Anuario de Filosofía del Derecho ${ }^{52}$, cuestionaba el uso indiscriminado del término "institución". Para él, una institución jurídica es un "plexo normativo, que tipifica y disciplina una clase de relaciones interhumanas reconoscible". Acudiendo al símil científico, -no en vano la de científico era otra de sus facetas junto con la de jurista-, afirmaba que "ciertas proposiciones jurídicas forman conjuntos planetarios con manifiesta unidad, convergiendo en torno a un común centro gravitatorio. Son partes dotadas de individualidad propia, perfectamente diferenciadas de las demás en su consistencia, en su función y en su finalidad. Tomadas en bloque, tienen un sentido cabal; constituyen una unidad significativa nítidamente deslindada, plenamente inteligible; pero ya insusceptible de división". Cada subespecie de relaciones humanas tipificadas sub nomine iuris se conceptúa, de este modo, como una institución jurídica, y así, son instituciones la ocupación, el matrimonio, la posesión, el embargo, la prescripción, etc. La clave se encuentra en que para determinar los problemas que no sean específicos de una institución jurídica concreta, hay que hacer una obra de reducción y simplificación institucional, pues existen instituciones jurídicas que "no son tipos jurídicos verdaderamente individuados, con fisonomía y caracteres propios, sino efectos de espejismos, consecuencias insoslayables, relaciones lógicamente necesarias de otros institutos jurídicos". Siguiendo esta idea de LOIS ESTÉVEZ, las verdaderas instituciones jurídicas resultan ser sólo las irreductibles, aquéllas que no son efectos de otras causas, "consecuencias lógicas del hecho de ser el Derecho como es". Y por ello, concluiría este autor que la "naturaleza jurídica" persigue un ideal eminentemente científico, que es la intelección genética; es decir, la comprensión de cómo adviene eso que se nos da bajo una institución jurídica, que no se logra sino "demostrando cómo una institución cualquiera no es sino implicación y consecuencia de alguna forma de valor jurídico primitiva" ${ }^{53}$.

51 E. P. HABA MÜLLER, Axiología jurídica fundamental, Editorial de la Universidad de Costa Rica, 2004, p. 62.

52 J. LOIS ESTÉVEZ, "Sobre el concepto de «naturaleza jurídica»", cit.

53 J. LOIS ESTÉVEZ, "Sobre el concepto de «naturaleza jurídica»", cit. 
Aun aceptando que la idea de "naturaleza jurídica" persiga ese ideal científico -lo cual no es incompatible con que su efecto inmediato sea cubrir una necesidad del lenguaje, como el $t \hat{u}-t \hat{u}$ de ROSS-, visto cuanto antecede, cabe preguntarse si asignar una naturaleza jurídica concreta a la prescripción del delito, considerada una institución a la vista del tratamiento unitario que se le da en la Parte General del Código Penal, no es acaso dar una personalidad independiente a algo que en sí mismo no es sino un conglomerado que puede reducirse a otras expresiones.

El Código Penal regula la prescripción de forma unitaria en su Parte General, pero, en lugar de esto, perfectamente podría señalar en su Parte Especial, a continuación de la descripción de cada delito, su plazo de prescripción o su imprescriptibilidad. Claro que resulta más cómodo sumar las ideas que tienen el mismo fundamento y responden al mismo fin, plasmando el resultado de esta operación en una sola proposición jurídica de la Parte General, de modo que a la idea de que transcurrido un tiempo " $\mathrm{x}$ " desde la comisión de un delito "a" ya no es necesaria la imposición de una pena, se suma la idea de que cuando transcurre un tiempo " $y$ " desde la comisión de otro delito " $b$ " tampoco es necesaria. Y así sucesivamente, hasta la construcción de una "institución" de Parte General, como es la prescripción del delito que, sin embargo, puede descomponerse en otras muchas proposiciones. Y es que, como observa HERNÁNDEZ GIL, en los Códigos, "La Parte general es (...) la prueba más palmaria, el exponente más acabado de lo que es y a lo que aspira la dogmática. Constituye el resultado de un proceso lógico completo. Viene a ser como una cima que se escala a través de un procedimiento rigurosamente inductivo. Con los elementos comunes de los conceptos generales integrantes del sistema se forman unos conceptos todavía más generales que son la quintaesencia del sistema: los puntos en que éste se unifica. Hay, pues, una doble abstracción. (...). Gran parte de la denominada «teoría general del derecho», con la que el positivismo quiere suplantar a la filosofía del derecho, se elabora, a su vez, sobre los materiales aportados por las partes generales de las distintas disciplinas" ${ }^{54}$.

Según MIR PUIG, en el Código Penal, las disposiciones de la Parte General no tienen otra función que la de precisar el alcance de los preceptos de la Parte Especial $^{55}$. La Parte General cumple así una función de gran utilidad, pero entraña también el peligro de alcanzar tal grado de abstracción de los conceptos o generalidad de su aplicación que nos lleve a olvidar las particularidades de cada uno de los supuestos a los que el concepto debe aplicarse. Por su parte, ÁLVAREZ GARCÍA, en un interesante artículo titulado "Relaciones entre la parte general y la parte especial del Derecho Penal"56 , recogía algunas de las críticas que ha recibido por la doctrina el mencionado proceso dogmático que culmina en las partes generales: ya en la Alemania nazi, los juristas alertaban sobre cómo en este proceso dogmático se había

54 A. HERNÁNDEZ GIL, Metodología de la Ciencia del Derecho, en Obras Completas, Espasa Calpe, Madrid, 1988, Tomo 5, pp. 115-116.

55 S. MIR PUIG, Derecho penal, Parte General, cit., p. 61.

56 F. J. ÁLVAREZ GARCÍA, "Relaciones entre la parte general y la parte especial del Derecho Penal", Anuario de Derecho Penal y Ciencias Penales, ISSN 0210-3001, Tomo 46, Fasc/Mes 3, 1993, pp. 1009-1030. 
llegado a una peligrosa mentalidad del «sí mismo», "una mentalidad que ha llevado a una especie de entificación de aquellos conceptos", olvidando que el Derecho está en función de la solución de cuestiones concretas "y no para afirmar principios que constituían un fin en sí mismos". Como ejemplo, el autor señala que conceptos como la "tentativa", el "dolo", la "imprudencia", el "encubrimiento", etc., desconocen momentos autónomos: esto es, que no estén en correlación con la figura del delito consumado. Tampoco existe un delito de imprudencia, de la misma manera que no existe un delito de dolo. La referencia a la imprudencia únicamente señala la parte subjetiva del tipo (aunque sin determinarla en todos sus extremos), por lo que se hace necesario completarla acudiendo a la Parte especial ${ }^{57}$. Pues bien, lo mismo puede decirse de la prescripción del delito, que no puede producirse en el vacío, ni "en sí misma", pues sólo tiene sentido decir que se ha alcanzado la prescripción en relación con un hecho delictivo concreto que, por el transcurso del tiempo, unido a la falta de persecución, ha dejado de ser punible, aunque no por ello, de acuerdo con la Teoría del delito, el hecho deje de ser típico ni antijurídico ni culpable.

Sucede que las Partes Generales de los Códigos no pueden desligarse de las Partes especiales, que surgieron antes en el tiempo ${ }^{58} \mathrm{y}$ de las cuales dependen. Pero que la regulación de las condiciones para que opere esta cualidad de cada delito no imprescriptible se unifique en una o varias disposiciones de Parte General no significa que la prescripción sea una auténtica "institución", al menos en el sentido que LOIS ESTÉVEZ asigna a esta palabra, esto es, que sea algo irreductible. Esas normas son simplemente el resultado de la fusión de todas las previsiones sobre la posibilidad de prescripción de los delitos de la Parte Especial del Código que pueden prescribir (pues existen algunos que conforme a la legislación positiva no prescriben nunca ${ }^{59}$ ), dando un tratamiento más o menos unitario a una cualidad común de estos delitos, pero que tampoco llega a ser homogéneo, pues debe tenerse en cuenta que en el Código Penal español existen distintos plazos de prescripción, así como condiciones específicas para que la prescripción opere en determinados casos, tampoco expresamente especificados en la descripción de cada tipo penal, por ejemplo cuando la víctima del delito es menor de edad ${ }^{60}$. Pero en cualquier caso, resulta evidente que no tiene sentido hablar de la prescripción desconectada del concreto delito que prescribe, pues "la prescripción" necesita de algo que prescriba.

57 Cfr. F. J. ÁLVAREZ GARCÍA, "Relaciones entre la parte general y la parte especial del Derecho Penal". cit.

58 La génesis histórica de las Partes generales que expone JUAN DEL ROSAL avala esta afirmación: "Hasta finales del siglo XVI no fue posible, en virtud de la carencia de un método adecuado, como por otro lado, por el estado de evolución de nuestro Derecho, la instauración de una Parte General del Derecho Penal... Es a partir del instante en que el pensamiento intelectual elabora una síntesis, cuando tropezamos con rudimentarias Partes Generales en nuestro Derecho. En Francia, con TIRAQUELLUS, 1558; en España, con COVARRUBIAS, 1557 y en Alemania con VIGETIUS, 1600". J. DEL ROSAL, "Reflexiones sobre el estudio de la parte especial del Derecho penal", en Estudios penales, Madrid, 1948, p. 21.

59 Cfr. art. 131.3-2 CP.

60 Cfr. art. $132 \mathrm{CP}$. 
Teniendo esto presente, resulta claro que la prescripción, actualmente regulada en el Código Penal como institución de la Parte General, no es sino una construcción legal formada por agregación y que puede descomponerse en múltiples proposiciones, cada una de las cuales señalará las condiciones para que la prescripción se produzca, tanto los requisitos de carácter general (transcurso de x años e inactividad procesal interruptora) como otras especialmente previstas en atención a circunstancias como la referida personalidad de la víctima y su minoría o mayoría de edad. Pero también podría atenderse a otros datos, relativos a las circunstancias del autor o a su comportamiento posterior a la comisión del delito. Y ello, porque no existe una única razón que pueda fundamentar la posibilidad de prescripción de todos los delitos, como demuestra la mera existencia de delitos imprescriptibles, resultando así que la gran variedad de argumentos que han pretendido fundamentar la prescripción (tales como el olvido social del hecho ${ }^{61}$, la presunta enmienda del reo ${ }^{62}$, etc.) se

${ }^{61}$ Sirven de base a esta teoría ideas como las plasmadas por ya en el siglo XVII por PUFENDORF, que en su De iure naturae et gentium afirmaba que "sería superfluo recordar en justicia los crímenes cuando tan largo tiempo hace desaparecer y olvidar su efecto, de manera que ninguna de las razones por las cuales se imponen las penas tenga ya lugar. CARRARA, en su Opuscoli di Diritto criminale, Prescrizione penale (interruzione) apuntaba: "Ahora bien, puesto que, después de un largo periodo de tiempo, como todos sentimos, el recuerdo del delito desaparece de la memoria de los ciudadanos, la opinión de la seguridad resurge naturalmente por obra posterior de la ley; y (en los casos de delitos más graves para los cuales reclama la ley un término más largo) el drama de la pena sería presenciado por una generación que no presenció el drama del delito: es evidente que, al castigar en esta condición de los ánimos, se despertaría en el público un sentimiento de piedad hacia el condenado, y vendría a producirse un efecto totalmente opuesto a aquel para el cual estaba destinada la punición". También PESINA, uno de los máximos patrocinadores de la retribución jurídica en Italia, afirmaba en sus Elementos de Derecho penal que "Con el transcurso del tiempo se recuerda menos el delito y la misma sociedad cambia, al cambiar los individuos que la constituyen. Es indudable que la sociedad humana debe negar las negaciones del Derecho contenidas en el delito, y debe hacerlo por el castigo del delincuente, pero debe hacer esto en tanto en cuanto tiene conciencia del mal realizado... en esta eficacia intrínseca de la conciencia del delito en la humana convivencia, se halla no sólo el fundamento de la prescripción de la acción penal, sino también el de la prescripción de la pena”. Cfr. F. M. PEDREIRA GONZÁLEZ, La prescripción de los delitos y de las faltas. Doctrina y Jurisprudencia, cit., pp. 124-125.

${ }_{62}$ La teoría de la enmienda presunta del delincuente viene a sostener que, con el paso del tiempo, se produce una variación en la identidad del sujeto, de modo que si se castiga un delito cometido mucho tiempo atrás, se está castigando a una persona distinta. JIMÉNEZ DE ASÚA refiere cómo PLATÓN hablaba ya de un fin preventivo de la pena, si bien lo hacía por cuenta de los sofistas, pues él mismo se adscribía a la teoría de la retribución. Sin embargo, no le atribuye sólo una finalidad utilitaria, sino que en su doctrina pueden hallarse antecedentes de la enmienda, de ahí que -como explica JIMÉNEZ DE ASÚA- "los utilitaristas citan con más orgullo a ARISTÓTELES, que en su Ética, mira la pena como una medicina en virtud de contrarios: el mal del delito y el temor del mal de la pena; y por ser los hombres más obedientes a la necesidad que a la razón, la pena es un acto de necesidad, que sólo es bueno en cuanto es necesario, aunque sería mejor para todos que no hubiera necesidad de ella". Cfr. L. JIMÉNEZ DE ASÚA, Tratado de Derecho Penal, Tomo II (Filosofía y Ley penal), cit., pp. 46-47. No obstante, como señala también JIMÉNEZ DE ASÚA, con cita de FAUSTO COSTA, puede considerarse exagerado hacer de las ideas de PLATON un antecedente del correccionalismo, pues "es natural que el filósofo de la Academia Ateniense no pudiera plantearse los problemas fundamentales del derecho de penar en los mismos términos en que 
han equivocado en su pretensión de universalidad, pues lo cierto es que la comisión de cada delito responde a un móvil distinto de su autor, que presentará además unas características criminológicas distintas. Asimismo, la inclusión de nuevos delitos en el Código Penal atendiendo a la protección de bienes jurídicos, en otros tiempos impensables -como pueden ser los relativos a la manipulación genética o incluso los de protección del medio ambiente- y que ha dado lugar a lo que se ha denominado "expansión del Derecho penal" "33, así como los distintos intereses que el Estado pretende salvaguardar cuando tipifica nuevos delitos, determinan que no pueda hablarse de un fundamento único de la prescripción.

En la propia Exposición de Motivos de la Ley Orgánica 5/2010, que introducía la excepción novedosa a la regla general de la posibilidad de prescripción consistente en la imprescriptibilidad de los delitos de terrorismo con resultado de muerte, afirmaba el legislador: "El fundamento de la institución de la prescripción se halla vinculado en gran medida a la falta de necesidad de aplicación de la pena tras el trascurso de cierto tiempo. La reforma se fundamenta en este punto en que tal premisa no puede cumplirse frente a conductas delictivas que presentan las características del tipo mencionado". Aunque se trata de un argumento circular, que no aclara la razón por la que, a diferencia de lo que ocurre con carácter general, tratándose de este tipo de delitos, el legislador considera que el presupuesto de la prescripción consistente en la falta de necesidad de aplicación de la pena por el transcurso del tiempo "no puede cumplirse", tal afirmación pone de manifiesto que el castigo de cada delito por el Estado responde a unos intereses distintos, aunque no siempre se expliciten, y ello tiene su correlación en materia de prescripción, que por eso no debe tener la misma regulación para todas las conductas consideradas criminales.

solemos plantearlos en nuestro tiempo". Cfr. L. JIMÉNEZ DE ASÚA, Tratado de Derecho Penal, Tomo II (Filosofía y Ley penal), cit., p. 57.

VON LISZT señala que cuando en 1656 la Baja Austria admitió la prescripción como una institución nueva, tomada del Derecho bárbaro, en su fundamento estaba contenida "la enmienda presunta del delincuente, motivo por el cual no debía haberse fugado del país, no cometido nuevo delito, ni haber gozado del provecho que pudiera haberle reportado la infracción. En los delitos de mayor gravedad la prescripción no era admitida”. F. VON LISZT, Tratado de Derecho Penal, Tomo II, $2^{\text {a }}$ edición, Madrid, Ed. Reus, 1929, p. 406; M. R. LA ROSA, La prescripción en el derecho penal, Astrea, Buenos Aires, 2008, p. 12.

En España, es de destacar la corriente de los llamados correccionalistas, para los que el único argumento razonable que justificaría la existencia de la prescripción sería la enmienda presunta del criminal, que haría innecesario recurrir ya a la pena, aunque tales ideas no hayan llegado a plasmarse en la regulación positiva de la institución. Así, para SILVELA, la prescripción del delito era una "causa de extinción de las acciones que nacen del delito", signo de corrección espontánea del delincuente, apreciable por "haber observado el reo una conducta intachable por un espacio de tiempo bastante largo para que pueda pensarse que ha adquirido el hábito o la virtud de la justicia, y que no es obra sólo de la hipocresía”. L. SILVELA, El Derecho penal estudiado en principios y en la legislación vigente en España, Madrid, 1903, pp. 355 y ss.

${ }^{63}$ Así, J. M. SILVA SÁNCHEZ, La expansión del Derecho penal. Aspectos de la Política criminal en las sociedades postindustriales, Editorial B de F, Montevideo - Buenos Aires, $2^{\mathrm{a}}$ edición, 2008. 


\section{LAS VENTAJAS DE UN PLANTEAMIENTO DISTINTO: LEGIS- LAR ATENDIENDO A LA PRESCRIPTIBILIDAD O POSIBILIDAD DE PRESCRIPCIÓN COMO CUALIDAD DE CADA DELITO DE LOS TIPIFICADOS EN EL CÓDIGO PENAL EN LUGAR DE ATEN- DER A LA PRESCRIPCIÓN COMO INSTITUCIÓN INELUDIBLE PARA TODOS LOS DELITOS}

$\mathrm{Si}$, cuando un delito prescribe, su autor ya no puede ser castigado, resulta claro que, desde el punto de vista de la dogmática penal, la prescripción afecta a la punibilidad, que hoy puede considerarse una categoría autónoma en la Teoría del delito, junto con la tipicidad, la antijuridicidad y la culpabilidad ${ }^{64}$.

Según COBO DEL ROSAL - VIVES ANTÓN, la punibilidad es consustancial a todo delito, pues "un delito sin punibilidad, un delito no punible, carece de sentido y en rigor no existe $y$, esto no obstante, un delito sin pena, no penado, es algo absolutamente irreal e ilógico, de acuerdo con nuestra legislación vigente" ${ }^{65}$. La punibilidad no es por tanto un elemento constitutivo del delito, sino una categoría meramente conceptual que sirve para poder definirlo. No obstante, en otro estudio, COBO DEL ROSAL distingue entre punibilidad en abstracto y punibilidad en concreto ${ }^{66}$. Tal distinción proviene de la doctrina italiana, donde se han intentado resolver así las dificultades que plantea la punibilidad como categoría sustantiva dentro de la estructura general del delito. Como explica MAPELLI CAFFARENA, la punibilidad en abstracto se refiere a un momento normativo como amenaza de la sanción penal y la punibilidad en concreto se refiere al momento aplicativo de la pena ${ }^{67}$. Pues bien, según COBO DEL ROSAL, la prescripción afectaría a la punibilidad concreta del hecho, entendida como posibilidad de que la infracción resulte efectivamente penada, pero no a la condición abstracta de punibilidad de la infracción, que es una condi-

${ }^{64}$ La categoría de la punibilidad, como explica MAPELLI CAFFARENA, procede en sus orígenes de BINDING, siendo la doctrina dominante en Alemania, pudiendo destacarse, entre los clásicos, junto con el citado BINDING, a RADBRUCH, BELING, LAN o KOHLER; y, entre los autores más actuales a JESCHECK, SCHMIDHÄUSER, LANGER, STRATENWERTH, SAX, WESSELS o RUDOLPHI. En la doctrina española, se muestran partidario de esta teoría, entre otros, SILVELA (con matices), ANTÓN ONECA, GIMBERNAT ORDEIG y MUÑOZ CONDE y JIMÉNEZ DE ASÚA. Este último aglutinó en el seno del concepto de punibilidad las condiciones objetivas de punibilidad, las condiciones de perseguibilidad y las excusas absolutorias. Cfr. B. MAPELLI CAFFARENA, Estudio jurídico-dogmático sobre las llamadas condiciones objetivas de punibilidad, Ministerio de Justicia, Madrid, 1990, pp. 50-51.

${ }_{65}$ M. COBO DEL ROSAL -T. S. VIVES ANTÓN, Derecho Penal, Parte General, cit., p. 201.

66 Cfr. M. COBO DEL ROSAL, "La punibilidad en el sistema de la Parte general del Derecho penal español”, Estudios Penales y Criminológicos, vol. VI (1983). Cursos e Congresos no 26. Servizo de Publicacións da Universidade de Santiago de Compostela. ISBN 84-7191-288-0, pp. 10-53. En internet en http://hdl.handle.net/10347/4293.

${ }_{67}$ Cfr. B. MAPELLI CAFFARENA, Estudio jurídico-dogmático sobre las llamadas condiciones objetivas de punibilidad, cit., p. 55. 
ción básica para que el delito exista y que debe entenderse como posibilidad legal de referencia y aplicación de la pena ${ }^{68}$.

Conforme a la moderna visión del proceso penal, que puede y debe perseguir otras finalidades legítimas, más allá de la mera aplicación de la pena ${ }^{69}$, la mera falta de punibilidad, en principio, no debería impedir la celebración del juicio. Sin embargo, sucede que, en la Ley de Enjuiciamiento Criminal, el hecho consistente en haberse alcanzado la prescripción es tratado como un óbice procesal que impide el enjuiciamiento del hecho delictivo conforme a su art. 675. Y ello pese a que, en primer lugar y según el estado de la ciencia del Derecho, un óbice de procedibilidad debe concurrir desde un principio y puede desaparecer, no siendo por tanto impedimento para que el hecho pueda ser juzgado posteriormente ${ }^{70}$.

Por otro lado, del estudio de las distintas condiciones de procedibilidad así reconocidas por la doctrina, se desprende que tales condiciones que permiten que se incoe el proceso necesitan, para producirse, un acto lícito en el que intervenga la voluntad humana, dirigido precisamente a permitir el inicio del proceso. En cambio, que el delito no haya prescrito depende de una causa ajena a la voluntad humana, esto es, de un hecho natural y que por lo tanto no puede calificarse de lícito o ilícito, como es el mero transcurso del tiempo, unido en primer lugar a la inactividad procesal -que por su parte hoy en día sólo puede estar justificada si se debe al desconocimiento no culpable del hecho punible por parte de los encargados de perseguir los delitos- $\mathrm{y}$ en todo caso a otro hecho ilícito como es la ocultación voluntaria del delito, pues salvo casos de error de hecho, error de prohibición, o concurrencia de algún tipo de imposibilidad, el delincuente podrá por lo general confesar su delito.

Sería deseable, pues, que la Ley de Enjuiciamiento Criminal abandonase la concepción de la prescripción como causa que impide el enjuiciamiento de los hechos, ya que no cabe duda de que la prescripción no puede afectar al delito como hecho del pasado, sino únicamente a la posibilidad de imponer en el momento presente una pena o medida de seguridad. Pero ello no debería impedir, por un lado, que pueda fijarse una verdad judicial de lo sucedido, siquiera para los delitos más graves o

${ }_{68}$ Cfr. M. COBO DEL ROSAL, "La punibilidad en el sistema de la Parte general del Derecho penal español", cit.

${ }_{69}$ El moderno proceso penal, configurado como un instrumento neutro, está abierto también (aunque muchos autores obvien este dato) a otras finalidades legítimas, como son la protección del derecho a la libertad, la protección de la víctima y la rehabilitación del imputado. Cfr. V. GIMENO SENDRA, Manual de Derecho Procesal Penal, cit., p. 37 y ss.

70 Así, el mismo COBO DEL ROSAL destaca cómo las condiciones de procedibilidad "afectan tan sólo a la iniciación del proceso penal". M. COBO DEL ROSAL, "La punibilidad en el sistema de la Parte general del Derecho penal español", cit.

En el Código Penal español actual, encontramos casos en los que el legislador exige, para que sea posible proceder contra determinados delitos, la denuncia previa de los hechos. Así, el art. 296 $\mathrm{CP}$, referente a los delitos societarios, o el art. 215.1-2 CP, que exige la obtención de la previa licencia del Juez o Tribunal que conociere o hubiere conocido del juicio en que se hubiesen vertido calumnias o injurias para poder deducir acción. También ha sido considerada requisito de procedibilidad la necesidad de obtención del suplicatorio (autorización administrativa para procesar), como es de ver en el Auto del Tribunal Supremo, Sala de lo Penal, de 9 marzo de 1998 (RJ 1998, 1779). 
que, sin serlo con carácter general, le hayan causado un perjuicio de gravedad a la víctima, realizándose así una labor de reconocimiento de las mismas y facilitándoles la rápida satisfacción de su derecho a la restitución, reparación o indemnización ${ }^{71}$, sin perjuicio de que, por razón del tiempo transcurrido, al haberse extinguido por prescripción la punibilidad del hecho concreto, no se imponga la pena al reo, o la impuesta no se llegue a ejecutar, o pueda ser sustituida por otra medida.

Asimismo, en atención a los fines que ha de perseguir la prescripción, y que tradicionalmente se han señalado como sus fundamentos, la posibilidad de que opere podría condicionarse a que el autor del delito haya llevado a cabo determinados comportamientos tras su comisión. Por ejemplo, haber procedido a reparar el daño causado, o haber abandonado la adicción que le determinaba a delinquir. A diferencia de los fundamentos tradicionales de la prescripción, cuya concurrencia es imposible de probar - como el olvido del hecho por la "sociedad", o la falta de necesidad de pena basada en una discutible y abstracta "reinserción social"-, la concurrencia de tales requisitos, a los que de lege ferenda podría sujetarse la prescripción, puede ser apreciada y probada o no en cada caso concreto, según parámetros previamente fijados, con pleno respeto al principio de legalidad y por ende garantizando una seguridad jurídica mucho mayor de la que suele invocarse como fundamento de la prescripción y que en la actualidad no es tal. Sujetar la posibilidad de prescripción a tales condiciones contribuiría también a un mejor logro de los fines de prevención general y especial que tradicionalmente se han asignado a la pena y que aún hoy pueden predicarse del Derecho Penal.

\section{BIBLIOGRAFÍA}

AGUILERA DE PAZ, E., Comentarios a la Ley de Enjuiciamiento Criminal, Ed. Reus, Madrid, 1924, Tomo V.

ALBALADEJO GARCÍA, M., La prescripción extintiva, Madrid, Colegio de Registradores de la Propiedad, Mercantiles y Bienes Muebles de España, 2004.

ÁLVAREZ GARCÍA, F. J., "Relaciones entre la parte general y la parte especial del Derecho Penal", Anuario de Derecho Penal y Ciencias Penales, ISSN 0210-3001, Tomo 46, Fasc/Mes 3, 1993, pp. 1009-1030.

BANACLOCHE PALAO, J., “Algunas reflexiones críticas en torno a la prescripción penal», Revista de derecho procesal”, ISSN 0213-1137, No 2, 1997, pp. 281-320.

71 Como ha puesto de manifiesto SUBIJANA ZUNZUNEGUI, en relación con las víctimas del terrorismo, la configuración de la prescripción en la Ley de Enjuiciamiento Criminal como obstáculo procesal "cercena el derecho de las víctimas y el interés de la comunidad en obtener, si hay fundamento probatorio para ello, una declaración pública, emanada de la autoridad dotada de neutralidad institucional, de que los daños causados fueron injustos y culpablemente causados por una o varias personas y, consecuentemente, excluye un pronunciamiento de que los mismos deben ser reparados por quienes los provocaron". I. J. SUBIJANA ZUNZUNEGUI, "La Justicia a las víctimas del terrorismo. Una exégesis de la prescripción compatible con el relato de las víctimas", Eguzkilore: Cuaderno del Instituto Vasco de Criminología, ISSN 0210-9700, No. 23, 2009, pp. 79-86. 
BULYGIN, E., La naturaleza jurídica de la letra de cambio, Buenos Aires, 1963.

CARRIÓ, G. R., Notas sobre Derecho y lenguaje, Ed. Abeledo-Perrot, Buenos Aires, 1965.

COBO DEL ROSAL, M. - VIVES ANTÓN, T. S., Derecho Penal, Parte General, Tirant lo Blanch, Valencia, 1991.

COBO DEL ROSAL, M., Tratado de Derecho procesal penal español, Centro de Estudios Superiores de Especialidades Jurídicas, Madrid, 2008.

- $\quad$ "La punibilidad en el sistema de la Parte general del Derecho penal español", Estudios Penales y Criminológicos, vol. VI (1983). Cursos e Congresos no 26. Servizo de Publicacións da Universidade de Santiago de Compostela. ISBN 847191-288-0, pp. 10-53. En internet en http://hdl.handle.net/10347/4293.

DEL ROSAL, J., "Reflexiones sobre el estudio de la parte especial del Derecho penal", en Estudios penales, Madrid, 1948.

DEL TORO MARZAL, A., Comentarios al Código Penal. Tomo I, Barcelona, 1978.

DEMÓSTENES, Discursos Políticos. Obras Maestras. Editorial Iberia, Barcelona, 1969.

GIMBERNAT ORDEIG, E., "La prolongación del plazo de prescripción para asesinato en la República Federal de Alemania (breve comentario y traducción de la toma de posición del Seminario de Derecho Penal de la Universidad de Hamburgo)", Anuario de Derecho Penal y Ciencias Penales, ISSN 0210-3001, Tomo 18, Fasc/ Mes 1, 1965, págs. 216-222.

GIMENO SENDRA, V., Manual de Derecho Procesal Penal, Universidad Nacional de Educación a Distancia, $3^{\mathrm{a}}$ edición, 2013.

GÓMEZ COLOMER, J. L., Constitución y proceso penal, Tecnos, Madrid, 1996.

GÓMEZ ORBANEJA, E., Comentarios a la Ley de Enjuiciamiento Criminal, Tomo I, Barcelona, Bosch, 1951.

GONZÁLEZ TAPIA, Ma I., La prescripción en el Derecho penal, Dykinson, Madrid, 2003.

HABA MÜLLER, E. P., Axiología jurídica fundamental, Editorial de la Universidad de Costa Rica, 2004.

HASSEMER, W., ¿Por qué castigar? Razones por las que merece la pena la pena. Traducción de Manuel Cancio Meliá y Francisco Muñoz Conde, Tirant lo Blanch, Valencia, 2016.

- “La medida de la Constitución”, en Constitución, derechos fundamentales y sistema penal, Tomo I, Semblanzas y estudios con motivo del setenta aniversario del Profesor Tomás Salvador Vives Antón, J. C. Carbonel Mateu, J.L. González Cussac, E. Orts Berenguer (dirs.) M. L. Cuerda Arnau (coordinadora), Tirant lo Blanch, Valencia, 2009, pp. 975 y ss.

HERNÁNDEZ GIL, A., Metodología de la Ciencia del Derecho, en Obras Completas, Espasa Calpe, Madrid, 1988.

JESCHECK, H. H. - WEIGEND, T., Tratado de Derecho Penal, Parte General, Traducción de Miguel Olmedo Cardenete, Comares Editorial, 5ª edición, Granada, 2002. 
JESCHECK, H. H., "La reforma del Derecho penal alemán. Fundamentos, métodos y resultados", Anuario de Derecho Penal y Ciencias Penales, 1972, pp. 629-642.

JIMÉNEZ DE ASÚA, L. Tratado de Derecho Penal, Tomo II (Filosofía y Ley penal), $4^{\mathrm{a}}$ edición, Editorial Losada, Buenos Aires, 1964.

LA ROSA, M. R., La prescripción en el derecho penal, Astrea, Buenos Aires, 2008.

LARENZ, K., Metodología de la Ciencia del Derecho, Ariel Derecho, Barcelona, $4^{\circ}$ impresión de 2010.

LISIAS, Discursos, Discurso contra Agorato (Discurso 13), Introducciones, traducción y notas de José Luis Calvo Martínez, Biblioteca Clásica Gredos, Madrid, 1988.

LOIS ESTÉVEZ, J., "Sobre el concepto de «naturaleza jurídica»”, Anuario de Filosofía del Derecho, ISSN 0518-0872, No 4, 1956, pp. 159-182.

MAPELLI CAFFARENA, B., Estudio jurídico-dogmático sobre las llamadas condiciones objetivas de punibilidad, Ministerio de Justicia, Madrid, 1990.

MEDINA CEPERO, J. R., El tratamiento procesal penal de la prescripción del delito, Dykinson, Madrid, 2001.

MIR PUIG, S., Derecho penal, Parte General, ed. Reppertor, 9a edición, Barcelona, 2011.

MORILLAS CUEVA, L., Acerca de la prescripción de los delitos y las penas, Granada, Colección de Estudios Penales de la Universidad de Granada, núm. 3, 1980.

- $\quad$ voz "Prescripción del delito y de la pena", en Nueva Enciclopedia Jurídica, vol. XX, Editorial Francisco Seix, Barcelona, 1993, pp. 269-295.

MUÑOZ CONDE, F. - GARCÍA ARÁN, M., Derecho Penal, Parte General. $5^{\mathrm{a}}$ edición. Tirant lo Blanch, Valencia, 2002.

NÚÑEZ FERNÁNDEZ, J., Curso de Derecho Penal, Parte General, Dykinson, Madrid, 2011.

PEDREIRA GONZÁLEZ, F. M., La prescripción de los delitos y de las faltas. Doctrina y Jurisprudencia, editorial Centro de Estudios Ramón Areces, Madrid, 2004.

- $\quad$ "La prescripción de las infracciones penales tras la reforma introducida por la Ley Orgánica 15/2003, de 25 de noviembre”, en La Ley, año XXVI, núm. 6249, martes 10 de mayo de 2005, pp. 1-10.

- $\quad$ "Breve referencia a la Historia de la prescripción de las infracciones penales. Especial consideración de la problemática surgida en el Derecho romano a través de dos aportaciones fundamentales", Revista de Derecho UNED, núm. 2, 2007, pp. 435-444.

Principios de Núremberg, Report of the International Law Commission covering its Second Session, 5 June - 29 July 1950, Document A/1316.

PUY MUÑOZ, F., "El Derecho y la naturaleza de las cosas", Anuario de Filosofía del Derecho, ISSN 0518-0872, No 12, 1966, pp. 75-94.

QUINTANO RIPOLLÉS, A., Comentarios al Código Penal, Editorial Revista de Derecho Privado, Madrid, 1966. 
RADBRUCH, G., Filosofía del Derecho, Editorial Revista de Derecho Privado, Madrid, 1944.

RAGUÉS I VALLÉS, R., La prescripción penal: fundamento y aplicación, Atelier, Barcelona, 2004.

REY GONZÁLEZ, C., en La prescripción de la infracción penal en el Código de 1995, Marcial Pons, $2^{\mathrm{a}}$ edición de 1999.

ROSS, A., Tû-tû, Traducción de Gerardo Rubén Carrió, Colección Nueva Teoría, Abeledo-Perrot, Buenos Aires, 1961.

SILVA SÁNCHEZ, J. M., La expansión del Derecho penal. Aspectos de la Política criminal en las sociedades postindustriales, Editorial B de F, Montevideo - Buenos Aires, $2^{\mathrm{a}}$ edición, 2008.

- $\quad$ "Nullum crimen sine poena? Sobre las doctrinas penales de la «lucha contra la impunidad» y del «derecho de la víctima al castigo del autor»", en Víctima, Prevención del Delito y Tratamiento del Delincuente, VV. AA., Comares, Granada, 2009, pp. 17-41.

SILVELA, L., El Derecho penal estudiado en principios y en la legislación vigente en España, Madrid, 1903.

SUBIJANA ZUNZUNEGUI, I. J., "La Justicia a las víctimas del terrorismo. Una exégesis de la prescripción compatible con el relato de las víctimas", Eguzkilore: Cuaderno del Instituto Vasco de Criminología, ISSN 0210-9700, Nº. 23, 2009, pp. 79-86.

VON LISZT, F., Tratado de Derecho Penal, Tomo II, 2a edición, Madrid, Ed. Reus, 1929. 